Rankin referred Dr Gee to the entry in her general practitioner's records for 14 May: "My heart pounds and pounds. Lasts up to three hours." Dr Gee agreed that he had carried out no physical examination of Mrs White between the end of March and 30 June 1983. Mr Rankin drew his attention to other entries in her general practitioner's notes: "short of breath," and "aching in the left arm"; to a report on an electrocardiogram ordered by her general practitioner, which indicated sinus tachycardia; and to a later note, on 17 June: "palpitation on exertion."

In response to Mr Rankin's suggestion that some of Mrs White's symptoms might have been to the thyroid extract Dr Gee quoted from several scientific articles to support his contention that most people with a normal thyroid develop a degree of tolerance to thyroid treatment. Mr Rankin emphasised to Dr Gee that his dose of thyroid extract was more than twice the normal replacement dose. Dr Gee replied that the normal replacement dose was an imaginary concept, and that thyroid extract was much less well absorbed than thyroxine or tri-iodothyronine.

Mr Rankin quoted extracts from several textbooks which advised against the use of thyroid medication and amphetamines in treating obesity. Dr Gee countered that these textbooks were written for a middle ground, not someone in his position. He accepted that there was a body of opinion that thought that thyroid hormones should be given only to patients with demonstrated permanent hypothyroidism. It would not be difficult to produce 50 articles supporting the use of thyroid hormones in the treatment of simple obesity uncomplicated by permanent hypothyroidism.

Counsel quoted from a textbook on the thyroid by Werner and Ingba (1971 edition): "The prolonged administration of doses of thyroid, in excess of $180 \mathrm{mg}$ or its equivalent daily is hazardous and completely unjustified." Dr Gee said he disagreed completely: there was no evidence to show that this was so. He said that $180 \mathrm{mg}$ was three quarters of his dosage $(250 \mathrm{mg})$.

$\mathrm{Mr}$ Rankin also referred Dr Gee to an extract from Goodman and Gilman's The Pharmacological Basis of Therapeutics, 6th edition, 1980: "Certain bizarre combinations of thyroid and other drugs (especially amphetamines) are still available. The use of thyroid or such mixtures for the purpose of weight reduction is dangerous and sudden deaths from cardiac arrhythmias have occurred. Obesity is not an acceptable indication for thyroid hormone therapy." Dr Gee denied that there was any record of sudden deaths from the use of either thyroid, or thyroid and amphetamine, in the dosages in which he used them.

MrRankin pressed Dr Gee on the tri-iodothyronine and thyroxine content of his thyroid extract tablets. Dr Gee disagreed with a table from de Groot and Stanbury, Thyroid and its Diseases (1975), which gave $100 \mu \mathrm{g}$ of tri-iodothyronine as the equivalent of $120 \mathrm{mg}$ of desiccated thyroid. He said that in giving patients $250 \mathrm{mg}$ of thyroid extract, he was giving the equivalent of about $50-60 \mu \mathrm{g}$ of triiodothyronine.

\title{
Inside and Outside Europe
}

\section{Medical journals in the Third World: problems and possibilities}

\author{
RICHARD SMITH
}

\begin{abstract}
Producing and editing the fourmal of the Sierra Leone Medical and Dental Association is difficult. The 500 doctors in the country don't always produce enough copy to fill the journal; much of what they do produce has to be heavily edited; the members of the association become upset when there are too many articles from outside Sierra Leone; printing costs are rising rapidly, making the whole operation vulnerable; pressures from advertisers are always a worry; and, as a final insult, many of the Sierra Leone doctors who write a good paper would rather have it published in the Lancet, the $B M \mathcal{F}$, or the East African Medical fournal. Yet despite these problems, the editor, Dr Durodami Lisk, who was trained in Newcastle, has no doubt that bringing out the journal is worth while and important.
\end{abstract}

\section{WHO is FIPP?}

Dr Lisk's problems were typical of those experienced by the eight other Third World health journal editors who gathered together last month for a conference in Copenhagen. The conference was organised by the International Federation of the Periodical Press (FIPP) together with the World Health Organisation, and the purpose was to bring together Third World editors with those from the developed world. Dr Ole Harlem, the editor of the Norwegian Medical

"British Medical Journal"

RICHARD SMITH, BSC, MB, assistant editor
Fournal and a member of the FIPP editorial committee, conceived the idea, and it took him three years to bring it to fruition.

FIPP represents about 20000 titles from around the world and is interested, the president Mr Fernando Bolin, a Spaniard, said, in both "big and small problems." The main reason for holding this meeting, Ms Jane Reed, the chairman of the editorial committee, explained, was that FIPP was concerned about the division between journalists in the developing and developed world. Those in the developing world feel that they are not listened to in the developed world, that they don't have the same access to information, and that their national views are misrepresented in publications from the developed world. FIPP hoped that by bringing together journalists and editors from the two worlds to discuss an issue "about which people could be objective" some of the hostility would disappear.

This "hidden agenda" remained hidden during most of the two day conference, but most of the editors seemed to feel that something was gained, if mainly the contents of a second conference. Information is, after all, as important as drugs, and maybe WHO should be producing an essential information list as well as an essential drug list. Sadly, the conference spent little or no time discussing what sort of health journals and information were needed in the Third World and much more time in discussing how the information should be packaged, distributed, and paid for. One "young idealist" (me) suggested that what was needed was not so much a plethora of small and inevitably second class New England Fournals of Medicine but more a cheap, practical, and widely available broadsheet that was directed at primary health care workers in remote areas. Maybe this suggestion was an example of the developed world patronising the Third World, but there was some mutter of approval before the meeting moved on. 


\section{Kenyan successes}

One Third World doctor who had long ago considered such an idea was Dr Vincent Akoko Orinda, a paediatrician from Kenya and one of the Third World editors who was clearly succeeding. Kenya has the East African Medical Fournal, which manages to continue operating successfully as a scientific journal in a developing country, but it also has an arresting medical magazine called Medicus, which most of the doctors in Kenya find essential reading (indeed, patients and politicians are also always keen to get a copy). Its appeal seems to lie in its relevance, its directness, its campaigns, and its many photographs of Kenyan doctors. It has campaigned on issues such as road safety and fluoridation, and the editors have gone out and gathered information and statistics where none existed in order to do this. It has also spoken out on medicopolitical issues, and its circulation jumped hugely when it caused the minister of health to resign from the medical association (the leading article that led to this resignation contained the memorable line: "Africans NEVER do two things-they NEVER BLUSH and they NEVER RESIGN.") The success of Medicus clearly has to do with its editors concentrating on the local health and political issues. Dr Orinda and his colleagues now plan to produce a monthly health magazine that will be aimed at both patients and primary health care workers.

Both the editor of the Lancet, Dr Ian Munro, and the editor of the $B M \mathcal{F}$, Dr Stephen Lock, were present at the meeting both to learn and to inform, but the preoccupations of the Third World editors were mostly quite different from those of these major international journals. Indeed, one of the main problems of Dr Rowland Tan Joo Siong from Singapore, editor of the Asian Fournal of Clinical Science, was that his potential authors all preferred to publish in international journals. Dr Povl Riis, editor of the Danish Medical Fournal, had some useful advice on this problem because he had had the same one in Denmark. Firstly, he recommended, pressure should be put on doctors (from grant giving bodies if necessary) to recognise that they had a responsibility to their own national scientific culture-which included publishing in national journals in the national language. Secondly, he suggested, it might often be possible for the authors to publish in both international and local journals, by using the Vancouver Group's recommendations on duplicate publishing. Thirdly, he advised editors to cultivate their local authors and to help them as much as possible, running courses on writing and statistics and rewriting their articles with them present.

\section{More editorial problems}

The problems of editors in resisting pressure from advertisers, sponsoring associations, and colleagues were also discussed. Dr Kayode Odosute of the Nigerian Medical Practitioner was able to get enough advertising only if he allowed advertisers space on the front page and below his editorial; he also found it difficult to refuse articles from colleagues working in the same hospital. Dr Durodami
Lisk from Sierra Leone brought a new twist to the sacred issue of editorial independence when he observed that pressure from sponsoring associations was right-after all the journal was for the members of the association not for the editor's personal satisfaction.

Refereeing papers didn't present much of a problem to many of the editors because they hardly got enough papers to referee. But Dr Gurumukh Sajanmal Sainani, the editor of the Fournal of the Association of Physicians of India, has to referee papers and is now rejecting $70 \%$ of the papers he receives. Dr Lock reminded the assembled editors of the advice in the last century that one of his predecessors had given on how to improve the fournal of the American Medical Association - "more papers and a bigger wastepaper basket." Today one important step towards this end was to get one's journal included in Index Medicus or Current Contents.

The main editorial problem of Dr Sun Mobin, the editor of the Chinese Medical fournal, was that his articles were all too long. Editors from the West pointed out that articles in their journals had been getting progressively shorter for many years and advised him to force the pace.

A whole day of the meeting was spent discussing problems of production, distribution, and finance. For Dr Sun Mobin the main difficulty was that his English language journal was printed on presses that were 60 years old; for other editors finance was the main problem, as emphasised by Constance Joan Westwood, from the Malaysian Medical Association. Distribution was a particular difficulty in the Philippines, Dr Eduardo De La Cruz pointed out. He is responsible for distributing several journals to many thousands of islands in the Philippines, and sadly the postmen often don't bother to deliver them. His solution was to use drug company representatives to distribute his journals, a revelation that sent a frisson through the editors from the developed world, but desperate problems need desperate remedies.

What should happen after the meeting? Several of those at the conference were worried that a firm future programme needed to be planned or the gains made at this meeting would be lost. A workshop type meeting, devoted to layout, style, and problems of technology, seemed to be the most popular idea, but nobody was quite sure where the money would come from. To save money one possibility was for regional meetings-none of the African editors, for instance, had ever met before. A simple aim that all agreed on was that for an international directory of Third World health journals, so that local or regional meetings could be arranged. A final suggestion was for a primer of Third World editing, emphasising the use of simple methods, and it was sad that the many practical suggestions thrown up at the meeting were heard by only nine Third World editors without there being any system for getting them to the many scores of those who weren't there or aren't even listed anywhere.

So was much achieved by the meeting? Only the future can answer that question, but a meeting of like minds who have never met before always holds some promise. The cooperation of FIPP and WHO may presage something important, for instance, and I hope that it will not be too long before a larger group can meet.
Is there risk in prescribing Restandol capsules and vitamin E $200 \mathrm{mg}$ for an elderly man (married to a younger wife) who has suffered all his life from difficulty in sustaining erection? He had a prostatectomy 20 years ago for benign enlargement of the prostate but is otherwise unusually healthy and active. He has been taking Restandol for 10 years, claiming that this improves his virility and general vitality. I have regarded this medication as a harmless replacement therapy. Am I correct in this view?

The major risk that this elderly man faces taking Restandol capsules (testosterone undecanoate) is from carcinoma of the prostate. A prostatectomy, whether by open enucleation or by transurethral resection, does not protect him from this risk. The incidence of unsuspected (incidental) carcinoma of the prostate found at necropsy in men in their 70s is about $40 \%{ }^{12}$ The incidence of such foci at transurethral resection of the prostate in this age group is also high, varying between $21 \%$ and $36 \% .{ }^{3}$ Prostatic cancer is under the control of androgenic stimulation, although there is no evidence that taking testosterone has anything to do with its aetiology. Although digital assessment of the prostate after prostatectomy may pose difficulties in interpretation, it would be wise to undertake regular routine rectal examinations of this man's prostate, as any suspicious change could then be detected. Without such evidence he is unlikely to be persuaded to discontinue his medication with Restandol if he has taken it for 10 years and believes it to be beneficial. Vitamin $\mathrm{E}$ seems to be given for various disorders, and, although there is no convincing evidence of its value, there are no adverse side effects. - J C GINGELL, consultant urologist and lecturer in urology, Bristol.

1 Franks LM. Latent carcinoma of the prostate. $\mathcal{X}$ Pathol Bacteriol 1954;68:603-16.
2 Halpert B, Schmalhorst WR. Carcinoma of the prostate in patients 70 to 79 years old. Cancer 1966;19:695-8.

Sheldon CA, Williams RD, Fraley EE. Incidental carcinoma of the prostate: a review of the literature and critical reappraisal of classification. $\mathcal{F}$ Urol 1980;124:626-3.1. 